\author{
Due to appear for publication with Routledge \\ Demetis, D (2017) The Systemic Role of Technology in financial \\ instability, in The Financial Crisis and White Collar Crime - Legislative \\ and Policy Responses, (Eds: Nicholas Ryder, Umut Turksen, Jon \\ Tucker), Routledge.
}

\title{
The systemic role of technology in the creation of financial instability
}

This chapter examines the role of Information Systems (IS) in creating financial instability by automating critical decision-making processes. By following a systems theoretical approach after Lee and Demetis (2016) and based on a few fundamental systems principles, the chapter identifies theoretical propositions about the nature of technology in constructing financial markets, and by extension, financial crises. The chapter draws from a few instances of the Dow Jones Industrial Average crisis of 2010, also known as the Flash Crash of 2:45 where \$1trillion was lost in market value within a few minutes. This is used as an example of technology out of control where algorithmic trading creates contingencies that affect how different stakeholders interact and re-act. Based on the entanglement of systems principles and technological interference, the main hypothesis that is developed in this chapter is that technology is largely set to lead in the creation of future instabilities and amplify the degree of uncertainty in markets. Ultimately, this aims to highlight the broader role of technology in the financial system, not as a tool that can be strictly harnessed to support transacting, but as a system in itself that has both emergent and unintended consequences, one of which escalates to the concept of a financial crisis.

Title/Affiliation: Lecturer, Hull University Business School, Centre for Systems Studies

\author{
Author bio \\ Dr Dionysios Demetis is a Lecturer in Management Systems at the Business School \\ of the University of Hull and holds a PhD from the London School of Economics. He \\ has been an Associate Staff member of the Information Systems Innovation Group \\ (ISIG) of the LSE, as well as an Adjunct Professor for the San Diego-based, Thomas \\ Jefferson School of Law in California where he lectured on International Compliance, \\ Anti-Money Laundering, the Bank Secrecy Act (BSA/AML) and Research \\ Methodology. He is the author of two books and a number of journal publications, \\ while his book on AML entitled 'Technology and Anti-Money Laundering' is the first \\ book to provide a coherent theoretical structure for AML research and practice, based \\ on Systems Theory. While at the LSE, he has contributed widely to a number of \\ research deliverables for the European Commission, but most importantly to the \\ domains of Anti-Money Laundering and Countering the Financing of Terrorism for \\ the Spotlight EU project, as well as the GATE EU Project.
}


This is an Accepted Manuscript of a book chapter published by Routledge in The Financial Crisis and White Collar Crime - Legislative and Policy Responses on 06 February 2017, available online: https://www.routledge.com/The-FinancialCrisis-and-White-Collar-Crime---Legislative-and-Policy-Responses/RyderTurksen-Tucker/p/book/9781138119970 


\section{Introduction and Review}

The role of technology in shaping financial crises is both fundamental and systemic. This chapter develops a theoretical model for such technological interference in the financial markets, based on principles of systems theory. This is done by the extraction of a set of theoretical propositions (designated as $\mathrm{P}_{1}, \mathrm{P}_{2}, \mathrm{P}_{3}, \ldots \mathrm{P}_{\mathrm{n}}$ ) that will be synthesized in the discussion. The case of the Flash Crash of the Dow Jones Industrial Average (DJIA) is also used for this purpose; from it, additional propositions are extracted for exploring the role of technology in this context.

Of course, in the academic literature, scholars have explored the intersection of technology/crashes from a number of different perspectives. For example, Brandt and Neumann (2015) explore the role of information technology in causing ambiguities by employing hypergame theory and render flash crashes on the actions of rational agents. Bréhier (2013) considers the role of technology (and its evolution) as a threat for the financial markets and prompts us to reflect on the variety of regulatory measures that need to be introduced (e.g. by revising the Market in Financial Instruments Directive - MiFID2) and the Market Abuse Directive (MAD2). In a similar trajectory, the importance of a regulatory intervention for market stabilization is stressed by Brewer, Cvitanic et al. (2013) as well as Ciallella (2015) who tracks the regulatory evolution of High-Frequency Trading and considers MiFID2. This is extended by Moosa and Ramiah (2014) who explore this in an Asian context where regulators considered imposing restrictions on high-frequency trading.

Baxter and Cartlidge (2013) reflect on the interactions between large-scale (technological) systems and the financial markets by pointing out that the level of complexity has risen significantly in how automation affects the financial system. In exploring the role of technology for the Flash Crash, Bethel, Leinweber et al. (2011) take a 'technology VS technology' approach: they explore the deployment of supercomputers to detect the problems that algorithmic traders may generate; this is directed towards the development of an automated 'early warning system' that would generate alerts towards unusual market conditions. At a micro-level, others propose 
risk-averse reinforcement learning for algorithmic trading (Shen, Huang et al. 2014), thereby placing technological emphasis on the individual 'rationality' of distinct algorithmic players. This approach does not seem to be shared by other scholars who view the Flash Crash as a disastrous consequence of computerized trading systems (Edwards 2010), unlike Moosa (2015) who dismisses the criticism directed at highfrequency trading and Stoll (2014) who views such developments as side-effects towards a path of more liquid and less costly markets. In turn, this is contradicted by an examination of how news affects electronic systems, where Cai, Harris et al. (2013) find that electronic markets are prone to greater stealth trading and post-trade volatility (expressing also concern for the proliferation of algorithmic trading and short-term volatility). At the same time, Treleaven, Galas et al. (2013) view algorithmic trading as a "secretive community where implementation details are difficult to find".

With the debate on the role of technology in the development of crises (like the Flash Crash) showing no signs of relaxation, this chapter positions itself in the context of this literature by taking a systems theoretical approach. While every recent financial crisis has largely been accelerated by technology (through the sheer speed of communication), the financial world has now reached a stage where the systemic role of technology is en route to dominate how the next financial crises will unravel.

Behind all of the underlying complexity, the reason for this is rather simple (albeit phrased in its extreme form): human beings are no longer making financial decisions. Algorithms have replaced human decision-making to a large extent. Nowadays, "the majority of volume is traded electronically, based on systematic computer algorithms. The ultra-high-speed version of algorithmic trading, high frequency trading, is estimated to account for over $77 \%$ of transactions in the UK market according to Tabb Group" (Sornette and Becke 2011, p.5). For example, in the foreign exchange market, it has been estimated since 2009 that more than 85 per cent of all trading is conducted by algorithms alone: in their study published by the board of governors of 
the Federal Reserve, Chaboud, Chiquoine et al. (2009) called this the 'Rise of the Machines'. This creates the following (intensifying) condition:

$\mathbf{P}_{1}$ : In the financial markets, algorithms dominate financial decisions and have largely replaced human decisions.

While several technological and financial forces are responsible for this development, one question that may immediately come to mind could be phrased as follows: aren't the designers of algorithms humans? So couldn't we think of algorithms (and technology in general when applied to the financial system) as an extension, an abstraction even, of human decisions? As we will see in our example further on with the Flash Crash in the Dow Jones Index, there are several obstacles to thinking about the role of technology in this way and several elements that complicate the circumstances further. In brief, the idea of technology as a force that imposes linearity and cause-and-effect relationships needs to abandoned (Reichel 2011). While technology at a micro-scale is controllable, technology at a macro-scale creates nonlinear emergent phenomena that infect any corresponding application domain with uncertainty and unpredictability (Backhouse, Demetis et al. 2005, Demetis and Angell 2006). There is a clear systemic role to technology within the global financial sector and it is becoming more and more a higher expectation that algorithms will be autonomous in their actions; this raises significant moral and ethical issues in the 'machine world' (Van Lier 2016).

The same pattern towards algorithmic dominance can be observed across multiple financial markets. Speed of transacting has become not only essential but constitutive of the way markets behave under algorithmic guidance. The role of algorithms in financial decisions has become so central that they are guarded as 'state secrets' due to their potential impact on the markets. A good example of this is the background to the Sergey Aleynikov story, a Russian computer programmer who was working for Goldman Sachs and was subsequently arrested by the FBI for stealing part of the algorithmic trading code. In the proceedings of this case before the United States 
Southern District Court of New York, the US attorney representing the government (Joseph Facciponte), stated the following (in the context of the severity of this incident and the dangers from the stolen computer code) - emphasis added below:

"The bank's profit margin will be eroded - and I'll explain why in a minute by the other competitive activity. In addition, because of the way this software interfaces with the various markets and exchanges, the bank has raised a possibility that there is a danger that somebody who knew how to use this program could use it to manipulate markets in unfair ways. What this program does is connect and draw information from stock exchanges around the country, and it draws them in very small increments of time. One of the bank officers described it as milliseconds of time. And it is very efficient at processing that stock information and sending to the bank's programs that conduct trades based upon algorithms that are developed by mathematicians and physicists" (USagainstAleynikov 2009, p.7-8)

What is rather evident - and astonishing-is that the same technological/algorithmic development that is used for profit making from one financial institution is depicted (by government officials!) as a perceived danger of 'unfair market manipulation' in the hands of someone else (based on the information the bank itself gave the government). So a major financial institution like Goldman Sachs can be entrusted to use this algorithmic technology in a sensible way but in the hands of someone else it could amount to manipulation? Of course the real question behind this is as follows: would regulators be in a position to unpack the effects of algorithms designed by mathematicians and physicists that operate across markets over milliseconds and en masse? The answer to that as we shall see is to the negative - this is a complex system where the multiplicity of interactions remains invisible. But in light of the aforementioned case and the significance of a single algorithmic platform (guided and executed by a single market player), the following proposition can be put forward:

P2: Through algorithmic trading, a single market player can create considerable effects in an extremely limited time-span.

Another consequence of these dynamics that are illustrated in the case above is the importance of security in protecting these algorithms. This opens up the possibility of 'computer hacking' the financial markets and cause algorithmic-generated crises, not 
by debilitating the financial system in itself but by trading within its algorithmic confines.

From the few examples discussed already we can see how the role of technology in the financial system is characterized by deep penetration effects instead of superficial technological use. The following section builds on this idea and extracts several propositions based on systems theory.

\section{Basics of Systems Theory and reflections for the financial system}

In what way is the financial system a system and in what way is a financial crisis a systemic phenomenon? This section approaches systems as objects of study in general and identifies further propositions that emerge directly from prominent scholars in the field of systems theory. This will help us connect the role of technology in dominating financial decision-making and develop the conceptual synthesis that ties in technology and financial instability.

First, it is important to recognize that the vision for the development of systems theory came in the early 1950s with the Society for General Systems Research. Bertalanffy (1950), Boulding (1956), Rapoport (1950) and then Miller (1978) sought to develop a meta-theory that would be used to describe different phenomena and apply across different fields. The whole endeavor has been called a science of synthesis (Hammond 2003) and applied across many fields: physics, biology, sociology, law, finance, etc. The generality of systems theory can be perceived as "the skeleton of science in the sense that it aims to provide a framework or structure of systems on which to hang the flesh and blood of particular disciplines and particular subject matters in an orderly and coherent corpus of knowledge" (Boulding 1956, p. 208).

A system can be defined as a "complex of interacting elements $e_{1}, e_{2} \ldots e_{n}$. Interaction means that the elements stand in a certain relation, $\mathrm{R}$, so that their behaviour in $\mathrm{R}$ is 
different from their behavior in an another relation, R'.” (Bertalanffy 1950, p. 143). Another way to think about this is that a system is constituted of its subsystems (and these by sub-subsystems, ad infinitum). This definition of a system must also be put into the context of the primary distinction that can be recognized across several branches of systems theory; that is the recognition that any system must be distinguished from its environment; the distinction between system/environment is fundamental. No system can exist without an environment (Bertalanffy 1969, Luhmann 1995, Luhmann 2006) and for any defined system, the environment is always more complex (Luhmann 2002). These very few starting principles are identified below as $\mathrm{ST}_{1}, \mathrm{ST}_{2}, \mathrm{ST}_{3}, \ldots$ and they have major ramifications analysed by Skyttner (2005, p.53) and expanded below with insights developed by other systems theoreticians (Von Foerster 1951, Bateson 1972, Beer 1985, Luhmann 1995):

ST1: Interdependence: A system is constituted of elements and relations (or of subsystems, sub-subsystems, etc). It is the interrelationship and interdependence of objects and their attributes that is significant; unrelated and independent elements can never constitute a system.

ST2: Holism: Holistic properties (at the level of the system itself) cannot possibly be detected by any analysis of the 'components' of the systems. However, it is still possible to define such holistic properties in the system. Properties that can be found at the level of the system but are spawned from the complex interactions of the system's components (and as such they cannot be reduced to the study of those components) are called emergent properties.

ST3: Goal seeking: Systemic interaction must result in some goal or final state to be reached or some equilibrium point being approached. However, within each system there are subsystems with different (and distinct) goals and due to the complexity of the environment, there is always uncertainty that cannot allow strict controllability of systems. Still, the system (e.g. an organisation) identifies itself with a strategic goal.

ST4: Transformation process: All systems, if they are to attain their goal, must transform inputs into outputs. In living systems this transformation is mainly of a cyclical nature.

ST5: Inputs and outputs: In a closed system the inputs are determined once and for all; in an open system additional inputs are admitted from its environment. In 
today's business environment, organisations can be conceived of as complex open systems.

ST6: Regulation: The interrelated objects constituting the system must be regulated in some fashion so that its goals can be realized. Regulation implies that necessary deviations will be detected and corrected. One can extend this at an operational level and think of such systems as self-regulating systems: systems that have the capacity to adapt themselves based on a set of rules and conditions.

ST7: Hierarchy: Systems are generally complex wholes made up of smaller subsystems. This nesting of systems within other systems is what is implied by hierarchy. As mentioned already this would follow the form of: systems $\rightarrow$ subsystems $\rightarrow$ sub-subsystems, ad infinitum.

ST8: Differentiation: In complex systems, specialized units perform specialized functions. This is a characteristic of all complex systems and may also be called specialization or division of labour.

ST9: Equifinality and multifinality: Open systems have equally valid alternative ways of attaining the same objectives from different initial conditions (convergence) or, from a given initial state, obtain different and mutually exclusive, objectives (divergence).

What propositions can we extract from the above high-level systems theoretical principles for the financial system and the concept of the financial crisis itself? We will take the above aspects and expand on them for the identification of such propositions. First, what we could identify as a financial system commences with the interrelationship and interdependence of the system's different elements. Hence, from ST1 we can consider the financial system as constituted of complex interdependencies that are significant for the system itself. From this, we can consider that:

P3: A financial crisis is a holistic property of the financial system and constitutes an emergent phenomenon. A crisis emerges out of the interaction of several interdependent components and cannot be attributable to a single transacting element.

Portrayed this way, the concept of financial crisis is viewed as an expression of the system itself. There may be an initial stimulus (that will lead to a financial crisis eventually) but neither the 'stimulus' (and how that is spawned) nor the pathway 
towards a financial crisis can be determined. A financial crisis is not something that can be predicted uniquely so that meaningful action can be taken - to a degree that it will stop the crisis from ever manifesting. The evidence for this is everywhere but mostly on the realization that no advanced mathematical/statistical technique, big data analysis or market interpretation has ever predicted a crisis (or its effects and unraveling extent). Ironically, the financial system itself, when reaching the realization that it generates contradictory descriptions of itself that lead to its own destabilization, has sought a way to create financial instruments for de-risking. The $2^{\text {nd }}$ order derivatives market can be seen as a paradoxical manifestation of this. But of course, one may "mention the volatility of the financial market with its new derivative instruments for simultaneously maximizing security and risk with unpredictable effects" (Luhmann 1997).

Risk and unpredictability are also present in the context of any system. If we take a specific organisation as an example of our $\mathbf{S} \mathbf{T}_{3}$ principle on goal-seeking then we may observe that different organisations (if we define those as our systems) will have different goal-seeking strategies. These are always time-dependent and depend on complex system/environment interactions. They also depend on the degree in which the system allows feedback from its environment in shaping its goal-seeking strategies. If we take a trading algorithm as the system to be examined then we can consider that:

P4: Algorithms launched from different financial players will have different goalseeking strategies. When activated and become part of the financial system, algorithms find themselves in a much more complex environment. They affect and are affected by that environment (in which other algorithms reside) in unpredictable ways. While each algorithm 'controls' its actions, the effects for the financial system as a whole are emergent.

Based on $\mathbf{S T}_{\mathbf{4}}$ and $\mathbf{S T}_{5}$, all systems transform inputs into outputs. This takes a number of varieties in the context of the financial system but there are several examples that can reflect this further. Taken the conceptual focus of this chapter in algorithmic processing then we can look at this process through that context. In algorithmic trading, selected inputs (like the price of a stock or the trading volume) can be chosen 
from an algorithm; the output then is an automated decision (e.g. buy/sell an X amount of that stock at that price). Even though such a transformation process seems to be controllable, there are environmental stimuli that algorithms consider automatically without human interference. Decision algorithms now take input from: a) the system of mass media - the algorithms deconstruct and analyse news automatically about the companies they are monitoring; for example, Bloomberg uses sentiment-analysis of company-news in order to classify news items as 'negative' news for a company (Bloomberg 2015); the algorithm can act on that 'automated' news feed and trigger a sequence of further automated buy/sell decisions, b) the wider system of the economy, where trading patterns are being monitored and fed into automated trading decisions that use numerical thresholds, c) the system of law, where legislative initiatives or guidelines (e.g. issued by the Securities and Exchange Commission) are deconstructed as logical restrictions, thereby forbidding certain courses of action for the trading algorithms (e.g. don't engage in abusive shortselling). Based on the exposition described above,

P5: Algorithms take inputs from the financial system in various ways (e.g. price, volume, news, restrictions) and transform these inputs into outputs that take the form of algorithmic decisions.

Based on P5 as stated above (and extrapolated from the preceding analysis), one thing that is worth emphasizing here is that inputs are allowed from the environment of each algorithm. This renders the totality of algorithmic trading as a complex open system; it also implies that any cause-and-effect relationships embodied by individual algorithms (through a strict rational logic in the form of: if this event occurs then execute a specified sequence) cannot be followed through at a macro-scale. Inputs from the environment are unpredictable and while each algorithm usually specifies specific thresholds through which the automated execution of decisions will be manifested, this is not always the case. As we will see in the case of the Flash Crash of 2:45 of the Dow Jones Index, at least one algorithm did not consider price fluctuations at all in its automated decision making but only volume.

This swift towards algorithmic decision making has implications for $\mathbf{S T}_{\mathbf{6}}, \mathbf{S T}_{\mathbf{7}}, \mathbf{S T _ { 8 }}$ and ST9 (regulation, hierarchy, differentiation and equafinality). While each algorithm 
is self-regulating (and human intervention may take place in critical parts of the process as and when required), the effects of algorithms become part of the environment (and then feed back as stimuli to the algorithms themselves). This circularity requires both differentiation and hierarchy to be dealt with but can never be accounted for as the complexity in the financial system supersedes any attempt at controlling the market.

The implications of the previous propositions can now be considered in light of further systemic elaborations. This is based on systems theorist Niklas Luhmann who developed systems science further and applied it to society and its subsystems (law, economics, politics, media, etc). While Luhmann's work is complicated, a basic diagram can assist us in conceptualizing his classification of systems, an adaptation based on (Luhmann 1990, p. 9, Moeller 2006):

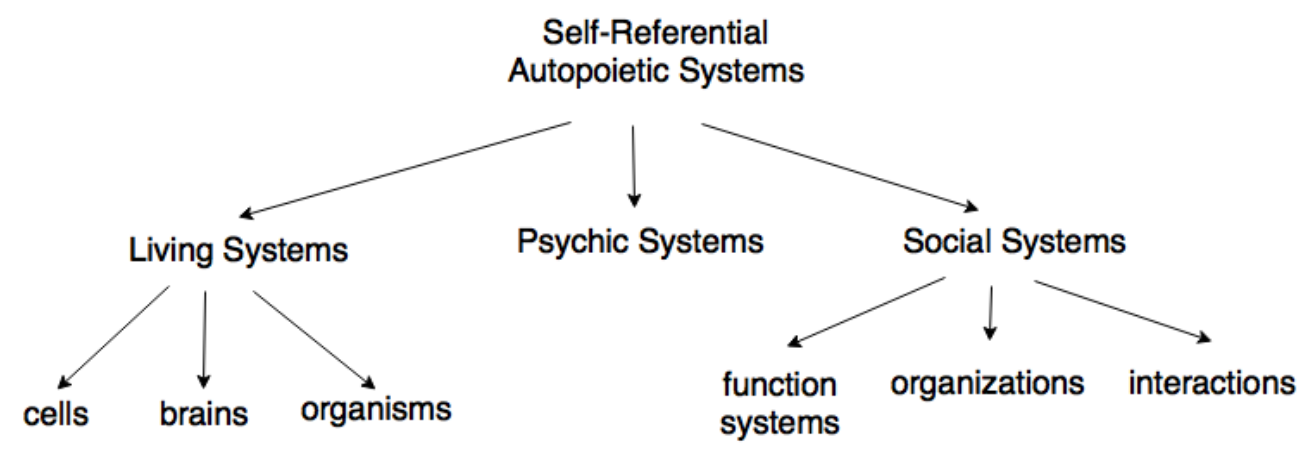

Figure 1: Classification of systems

"Living systems" refer to biological entities while "psychic systems" refer to the minds of human individuals. Our focus here is "social systems". For Luhmann, the only function that is primary at the level of society itself is communication. Hence, social systems can be conceived of as communication systems; communication involves “a unity of announcement (Mitteilung) or 'utterance' based on (Seidl 2009, p.28)., information (Information), and understanding (Verstehen)" (Moeller 2006, p. 22). Any act of communication within social systems (or subsystems of society like the financial system) involves these three elements. Financial communication in particular can be considered as: 1) announcements/utterances where stakeholders initiate buy/sell decisions; these utterances are considered as 2) information from other stakeholders that engage with them, and then, based on their 3) understanding (a 
cognitive interpretation of the received information), the latter decide to act and initiate their own 'utterances'. With the development of algorithmic trading, this fundamental model of communication has changed drastically since the last part - of cognitively interpreting the received information is missing. We can no longer speak of understanding (Verstehen) in communication through algorithmic processing. This allows us to consider that:

P6: The development of algorithmic trading is based on a faster form of communication that eliminates the step of cognitive understanding in the process of communicating. This is replaced by algorithmic 'understanding' - a limited logical type that collapses understanding to mere information processing.

This shift in how humans communicate (with the assistance of technology) to how algorithms communicate (in the absence of human interference) has additional implications for how we can depict financial interactions between stakeholders. For example, in the economic system, any interactions that can be considered as economic communications involve the "satisfaction of needs"; the meaning (or what Luhmann calls the "code") of the economic system is expressed through the unity of the distinction between "payment/non-payment". Similar conditions arise for other subsystems of society (Luhmann calls these function systems) like the legal system, where communication involves the "regulation of conflicts" and the code is expressed based on the distinction between "legal/illegal" (Moeller 2006, p.29). In this regard, "codes" are binary distinctions that encapsulate the identity of a core system in society and support communication across all of their subsystems. "Organizations," as another form of social system, also conduct communication, but Luhmann specifically conceptualizes organizations as conducting the communication of decisions, and hence are "systems of decisions" (Moeller 2006, p. 31).

In considering each social subsystem (like the financial system) through an expression of a fundamental 'binary code', Luhmann depicts such a code as the fundamental basis upon which the identities of these subsystems rests. This fundamental code cannot be resolved - such a process would result to a paradox. For example, paradoxically, the legal system cannot define what is legal or illegal (Luhmann 2004) - this is defined through operations. "...while the distinction between legal and illegal 
can be maintained for individual coding, the legal system as a unity can never decide the basis of what is legal or illegal. It can never apply the code to itself as a system. There is no foundational value establishing what is legal or illegal, only operations." This creates a unique self-reference that is always underpinned by a paradox: "this enables the legal system to operate legally (!) by declaring that something is legal or against the law".

Hence, the basic relationship behind the 'code' of the financial system and technology can be expressed as follows:

$\mathbf{P}_{7}$ : Technology as it is currently being used in the financial system creates a metaorganisation: a system of automated decisions that shape the 'code' of the financial system itself and influence the primary distinction of payment/non-payment.

In other words, technology itself imposes its logic in shaping the very identity of the financial system. Through technologically-induced automated decisions, the code of the financial system (payment/non-payment) is expressed. Algorithmic operations constitute the basis for these expressions at an operational level.

Additional systems theoretical aspects can help us to establish further general propositions upon which we can build reflections for the role of technology in the development of financial crises (following the March 2010 event descriptions in the next section). Another important aspect that has already been mentioned and is emphasized further here is the distinction between system/environment. For Luhmann, the environment is not a residual category (here system, there environment), but constitutive of the existence of the system. Between any defined system (and its environment) there is a structural coupling and one cannot exist without the other. This ontological binding between system and environment has considerable implications if applied to the role of technology in the financial system. If technology underpins the financial system as a system then what is its environment? Where does the technologically-driven financial system receive its information from? There are several possibilities here but other function systems in society (like the legal system or the system of mass media) would be the appropriate candidates as already mentioned. This drives the need for further automation in the financial system itself (and an unstoppable excessive reliance on technology) as the precondition for 
system/environment interactions now becomes the automation of the environment, or indeed, the automation of specific information-dependency paths from the environment of the financial system. This force has created several contingencies and few examples can be found here: one that has already been mentioned is the integration of sentiment analysis by automated means in order to filter negative news of companies. As Hendershott et al frame it:

"...some algorithms are designed to sniff out other algorithms or otherwise identify order flow and other information patterns in the data. For example, if an algorithm identifies a sequence of buys in the data and concludes that more buys are coming, an algorithmic liquidity supplier might adjust its ask price upward. Information in newswires can even be parsed electronically in order to adjust trading algorithms." (Hendershott, Jones et al. 2008)

So what if the information in newswires is also computer-generated (or is an error or ambiguous)? How can we perceive the function of technology then? In May 2014, the Associated Press (AP) announced that the majority of stories about US earnings for business news reports will eventually be produced by using automated technology. Lou Ferrara, Vice President and Managing Director of AP mentioned that in this way "instead of providing 300 stories manually, we can provide up to 4,400 automatically for companies throughout the United States each quarter" (Colford 2014).

So automation in one function system (mass media) is being used as input for automation in another function system (financial system). This level of automated couplings should really concern us, along with the fact that automated decisiontaking is occurring in each case. In fact, automated decision-taking is being used as input for further automated decision-taking. This process of 'automation out of automation' across the financial system indicates the self-referential character of this condition and how technology is starting to hijack financial decision-making. Through the medium of algorithms, automation re-inserts itself into...itself. In systems terminology this is an autopoietic system (Maturana and Varela 1998): "a system that produces itself. It is perhaps best understood in contrast to an allopoietic system, such as a factory, which takes in materials and uses them to produce something other than itself' (Buchanan 2010). But in the case of the financial system with its current use of technology, automated decisions produce further automated decisions. 
An incredible example of this over-reliance on algorithmic computerization comes from a recent example of an automated robot (i.e. an online 'bot') that scanned websites to extract investor-relevant information from the public domain. An early posting about Twitter's Q1 results on their investor relationship website (managed by Nasdaq) was mistakenly placed online for a mere 45 seconds - plenty of time for the algorithms of Selerity (a company based in the US) to scan and tweet them on without any human intervention. That one tweet wiped $\$ 8$ bn off Twitter's value in a single day (Simmons 2015). The above reflections demarcate a unique space for how technology in the financial system affects other technology in a self-referential way.

P8: Technological interactions in the financial system are developing into autonomous interdependencies that affect each other in a self-referential manner.

Self-reference (that remains part of the core theoretical architecture of Luhmann's Systems Theory (Luhmann 1993, Luhmann 1995, Luhmann 2002, Luhmann 2002, Luhmann 2004) denotes the ability of systems to refer to themselves and replicate the system/environment distinction internally. Conceptualizing technology in this way reinforces the description of technology as a system that collects information about its own functioning and this in turn can contribute towards a change of its functioning (Geyer 2002).

A fascinating expression/example of the above contingencies can be found in the context of our example, the Flash Crash of the Dow Jones Index. Through this example, we will extract additional propositions for our discussion.

\section{Flash Crashing the Dow Jones Index: A new role for technology and developing a financial crisis}

While a complete reconstruction of the market events of May 6, 2010 (what has become known as the 'Flash Crash of 2:45') is beyond the scope of this chapter, several critical aspects that relate to the role of technology in its development will be reviewed. One thing worth mentioning up-front is that the complexity of the case itself, and the multi-dimensional role of algorithmic traders within it, has made it almost impossible to deconstruct the case in its totality - this is admitted in several 
official reports (like in the first source listed below). Once again, the purpose of this section is to extract propositions from this case; these propositions, combined with those extracted above from systems theory, will allow us to synthesize the development of the conceptual construct for the (current and future) role of technology in financial crises. The main sources being used for extracting quotations/propositions and the main findings of the Flash Crash include:

i) The Report of the Staffs of the U.S. Commodity Futures Trading Commission (CFTC) and Securities \& Exchange Commission (SEC) to the Joint Advisory Committee on Emerging Regulatory Issues.

ii) The UK report on 'Crashes and high frequency trading' from the Government Office for Science (The Future of Computer Trading in Financial Markets - Foresight Driver Review - DR 7)

iii) A perspective for Certified Public Accountants when Advising Investors entitled "Understanding the 'Flash Crash' " that summarizes the basic characteristics of the Flash Crash in a succinct way (Betancourt, VanDenburgh et al. 2011).

First, in order to set the scene, it is important that we put this in some context. Following uncertainty and generalized market turmoil in the possibility that the Greek government might default on their sovereign debt, market sentiment was broadly negative and "was already affecting an increase in the price volatility of some individual securities" (CFTC/SEC 2010, p.1). The key trends in the timeline before the 2:45pm Crash are as follows:

1) Around $1 \mathrm{pm}$, a number of volatility pauses were triggered on the New York Stock Exchange (NYSE); individual equities began to increase above average levels. 
2) The S\&P 500 volatility index rose at $22.5 \%$ by $2.30 \mathrm{pm}$. Investors engaged in "flight to quality" and the Dow Jones Industrial Average (DJIA) was down by $2.5 \%$ due to the selling pressure.

3) Buy-side liquidity in the "E-Mini" and the "SPY" (the E-mini S\&P 500 futures contracts and the S\&P 500 SPDR exchange traded fund) had suffered a 55\% and $20 \%$ declines respectively

4) At 2.32pm, a large fundamental trader (a mutual fund complex) "initiated a sell program to sell a total of 75,000 E-mini contracts (valued at approximately $\$ 4.1$ billion) as a hedge to an existing equity position" (CFTC/SEC 2010, p.2)

Perhaps the last step is considered to be one of the critical interventions as the large trade was conducted via an automated execution algorithm. While the single fundamental trader is not solely responsible for the Flash Crash (and the exact reason is not known), it is important to put this into some further context. Usually, a customer makes a choice of how much human judgment is involved when executing the trade. Also, a customer can choose to enter orders manually into the market or engage a third-party that will execute a block trade and manage the position.

However, in this case, the trader "chose to execute this sell program via a ..."Sell Algorithm" that was programmed to feed orders ... but without regard to price or time" (CFTC/SEC 2010, pp.2-3). The algorithm only took volume into consideration. But while the initial problems were indeed created by the algorithm of the fundamental trader, they were then "amplified by the strategic behavior of the HFT" (Sornette and Becke 2011, p.11). This created a self-referential phenomenon; a circularity where technology $A$ excited technology $B$ and then that fed back to technology A recursively. Indeed, as the initial sell pressure created by the "Sell Algorithm" was absorbed by High-Frequency Traders (HFTs), - at about 2.44pm - 
HFTs started to sell contracts aggressively and traded about $33 \%$ of the total trading volume. Then the "Sell Algorithm used by the large trader responded to the increased volume by increasing the rate at which it was feeding the orders into the market, even though orders that it already sent to the market were arguably not yet fully absorbed" - emphasis added (CFTC/SEC 2010, p.3). This can be perceived as a "negative spiraling effect ... (where)... HFT may have a destabilizing effect through its endogenous self-excitation nature within the (small) pool of participants" (Sornette and Becke 2011, p.11). From this, we can infer that:

P9: A technological subsystem like the Sell Algorithm can excite another technological subsystem (e.g. HFTs) and the effects can recursively affect the Sell Algorithm.

The events that unfolded in the stock market saw the biggest daily stock market collapse of the Dow Jones Industrial Average on Thursday May 6th of 2010 popularly known as the Flash Crash of 2:45. The DJIA plunged 998.5 points, and following almost five months of investigations, the Security and Exchange Commission (SEC) along with the Commodity Futures Trading Commission (CFTC), attributed the decline to, almost exclusively, the automated execution of orders. However it is important to stress that

\footnotetext{
"the exact reason or reasons for the so-called flash crash remain obscured by the mechanics of the electronic trading systems that execute millions of buy and sell orders during the course of a single trading day. Some initially blamed the crash on a "fat finger," while others contend that essentially unregulated electronic trading platforms were the culprit. Others even questioned whether terrorists or hackers were behind the dramatic drop" (Betancourt, VanDenburgh et al. 2011, pp.40-41).
}

The key lesson from this is that the crash cannot be attributable to any single algorithm or system in particular. It is a systemic phenomenon that emerges out of the complex interaction of multiple automated execution technologies. 
So whatever the complex automated configuration that created the conditions for the crash, it is quite clear that without the possibility for algorithmic trading at that scale, the flash crash would not have been possible. According to the testimony of SEC Chairman Mary Schapiro to the US Congress, this was mostly due to "automated trading systems that follow their coded logic regardless of outcome, while human involvement likely would have prevented these orders from executing at absurd price" (Schapiro 2010, p.7).

Of course, the financial markets are not the only ones that suffer from such conditions. As another example, the algorithmic definition of prices on Amazon.com faced similar 'feedback loop' effects; Amazon vendors "use algorithmic pricing to ensure that they can automatically change their product prices based on a competitor" (Solon 2011); this led to a book entitled "The Making of a Fly" by evolutionary biologist Peter Lawrence came to be priced at $\$ 23,698,655.93$ (plus $\$ 3.99$ shipping)! The unpredictability with which automated algorithms feed off each other creates emergent conditions that can destabilize any system that technology itself penetrates.

For the financial system, the implications are clear:

P10: Automated systems follow their coded logic regardless of outcome. The demand for millisecond transacting creates another version of the financial system that will be drawn into a war between algorithms.

Whereas in the crash of 1987 (October $19^{\text {th }}$ ) some Wall Street brokers simply declined to pick up their phones to avoid orders from their customers, in the new conditions imposed by technology, algorithms themselves become 'responsible' for shielding the market against further crash. For example, while the chaotic behaviour was continuing in the flash crash, the Stop Logic Functionality of the Chicago Mercantile Exchange (CME) was triggered in order to stop any further decline. This means that: 
P11: In order to address the emergent uncertainties from the automated behaviour of buy algorithms and sell algorithms, there is now a need to include both Stop and Pause algorithms.

Further complications can be considered in how more technology is actually emerging in order to deal with (and also exploit) the unpredictability and instability spawned by technological interactions. For example, new "crash algorithms will likely be developed to trade during periods of market stresses in order to profit from these periods" (Sornette and Becke 2011, p.4). One can consider here algorithms that are designed to find the digital footprint of each other and collaborate in specific market conditions, thereby creating unfair algorithmic competition; and indeed, with the increasing attention that has been given to information security and cybersecurity breaches (Dhillon and Backhouse 2000), automated financial trading may become subject to hackers or terrorists that will seek to create financial instability deliberately (e.g. by deactivating/modifying a stop algorithm, etc). This is certainly a real possibility that would be devastating if cybercriminals managed to conduct a malicious flash crash attack (Erra 2011). Whatever the destabilization effect, the speed of such transacting and the practical elimination of the human factor leads to an algorithmic financial war, where the algorithms will not only structure the market (by automated execution) but also the crises (by creating complexity in automated transacting), the exploitation of the crisis (by crash algorithms), and the response to the crisis (by stop/pause algorithms). The net effect of these contingencies are bound to lead to several high-level conditions for the systemic function of technology in financial markets; these will form the basis for examining the systemic role of technology in financial crises.

Hence, it is important to recognize that the very ontology of a 'financial crisis' is inextricably bound with the concept of the market as a system. A financial crisis, any financial crisis is not necessarily the result of bad decision-making. Any decision involves taking one risk over another risk. The development of new financial products/instruments/techniques accentuates this contingency. Thus, any financial decision is an approach that signifies the immediate need to cut down on the complexity of the market - simplify the uncertainty - and make a selection. From all 
the noise of the market, such a selection is unavoidable as no single entity (human or algorithm) can monitor concurrently all financial interactions taking place at any given point, or account for the myriad complex (and often invisible) organizational phenomena before these come to be announced and reflected on stock market prices.

This sequence of complexity-reduction to unavoidable risk highlights the contingency that crises are systemic and are not - strictly speaking - controllable.

\section{Discussion}

From the aforementioned analysis, the following propositions have been developed for the systemic role of technology in financial crisis. These are consolidated below in Table 1.

\section{Propositions Developed}

P1: In the financial markets, algorithms dominate financial decisions and have largely replaced human decisions.

P2: Through algorithmic trading, a single market player can create considerable effects in an extremely limited time-span.

P3: A financial crisis is a holistic property of the financial system and constitutes an emergent phenomenon. A crisis emerges out of the interaction of several interdependent components and cannot be attributable to a single transacting element.

P4: Algorithms launched from different financial players will have different goalseeking strategies. When activated and become part of the financial system, algorithms find themselves in a much more complex environment. They affect and are affected by that environment (in which other algorithms reside) in unpredictable ways. While each algorithm 'controls' its actions, the effects for the financial system as a whole are emergent.

P5: Algorithms take inputs from the financial system in various ways (e.g. price, volume, news, restrictions) and transform these inputs into outputs that take the form of algorithmic decisions.

P6: The development of algorithmic trading is based on a faster form of communication that eliminates the step of cognitive understanding in the process of 
communicating. This is replaced by algorithmic 'understanding' - a limited logical type that collapses understanding to mere information processing.

$\mathbf{P}_{7}$ : Technology as it is currently being used in the financial system creates a metaorganisation: a system of automated decisions that shape the 'code' of the financial system itself and influence the primary distinction of payment/non-payment.

P8: Technological interactions in the financial system are developing into autonomous interdependencies that affect each other in a self-referential manner.

P9: A technological subsystem like the Sell Algorithm can excite another technological subsystem (e.g. HFTs) and the effects can recursively affect the Sell Algorithm.

P10: Automated systems follow their coded logic regardless of outcome. The demand for millisecond transacting creates another version of the financial system that will be drawn into a war between algorithms.

P11: In order to address the emergent uncertainties from the automated behaviour of buy algorithms and sell algorithms, there is now a need to include both Stop and Pause algorithms.

The above propositions suggest a rather bleak scenario where financial crises may be starting from environmental stimuli (of real conditions and uncertainty - e.g. the Greek crisis) but then become part of hyper-complex millisecond transacting system that is largely uncontrollable at a macro-level. At the basis of this condition is the delusion behind the use of such Information and Communication Technologies (ICTs) - and their broader role in the financial system. Unfortunately, ICTs are usually considered to be a 'tool' that can be strictly controlled; however, the belief that the deployment of technology is largely controllable is not justified (Dreyfus, Dreyfus et al. 1986, Angell 1993). In fact, "technology is widely depicted as an unproblematically beneficial force for human progress ... technology is widely understood as simply applied science" (Scharff and Dusek 2014, p.9).

Technology however, in light of the systemic description and the propositions put forward in this chapter can be considered to "irritate society in a way that social reality is created by technology" (Reichel 2011, p.105). This re-description has profound implications for the financial system as it is not the human decision makers 
that use technology as a tool in order to make financial decisions. Based on the propositions extracted theoretically (and from our example on the flash crash), the situation seems to be reversed: technology dominates financial decision-making and human beings are there as the back-up plan to 'recalibrate the systems' when that will be required. Ironically, one of the things that humans re-assess in cases where automated trading needs to pause is "the ability of their (automated) systems to handle the very high volume of trades and orders that they were processing" (CFTC/SEC 2010, p.4). In this context, we can re-conceptualize technology in the financial system (Reichel 2011) and claim that technology is shaping the market itself through a complex nexus of (almost invisible) automated decisions. Consequently, technology is bound to shape the future of financial crises by assuming a more central role in how financial decisions are made with minimal (or no) human intervention.

In order to consider the implications of technological domination in an everexpanding number of social systems (like the financial system), we need to reflect on how the automated replacement for human decisions substitutes human decisionmaking. As shown in the case of the flash crash of the DJIA, technology initiates noncontrollable events; these emerge from complex interactions and feedback loops that develop very quickly (in our case over milliseconds). By allowing complex configurations of manual decisions to be automated, we (as humanity) have allowed technology to take responsibility over financial (and other) decisions. At the same time, technology is providing a proxy for shifting responsibility to automated decisions. This also "makes it very difficult for regulators to understand what is happening in the market" (Betancourt, VanDenburgh et al. 2011, p.42), a contingency that is rather desirable for many individual investors and financial institutions. If little or no human involvement takes place then humanity can be considered as an afterthought in the society of computers, in which computers largely shape, construct, re-construct, and observe financial reality. This leaves us with a condition where humanity can only react to how computers shape financial reality.

In this context, it would appear that the original designs of the algorithmic/computer logic are considered almost irrelevant. Indeed, an additional lesson from the Flash Crash is that "there was no 'big glitch', no fat-finger error or unforeseen computer 
error that triggered the crash. Instead, nearly every firm in the market at the time did precisely what it thought was rational according to current regulations" (Arnuk and Saluzzi 2012, p.179). So while every human designer of algorithmic practices had 'imbued' rational behaviour to the automated decision making processes, the emergent uncertainty from complex interactions created instability. The type of algorithmic complexity created at the level of the market cannot be simply 'unpacked' and examined; it is impossible to monitor the algorithmic logic of each automated buy/sell decision and the network of interactions that are technologically facilitated.

Against this background, technology becomes the critical proxy through which the financial system also observes itself. Technology is set up in order to assist in the automated execution of tasks, but is then recursively affected by the output of such automated executions; it 'accepts' such output as if they represent an un-interfered financial reality of strictly controlled technological operations. Algorithms in effect, have become patterns of decisions and not merely the proxies through which decisions are manually controlled. In systems theoretical terms (Luhmann 2002), it can be said that algorithms decide what becomes automated and unavoidably, at the same time, what is left un-automated. Coupled with a domain like the financial system this implies that the automated/non-automated decisions prescribed by algorithms are transcending into the financial system itself, into the social sphere, thereby designating what is criminal/non-criminal, what is marketable/nonmarketable, what is public/private, etc, even what is legal/non-legal. To frame it differently, algorithms cut down the complexity that is unmanageable by human beings, and in doing so, impose their presuppositions via the 'logic' they are given by their creators.

Where this global reliance on technology will lead is of no telling. Systemic automation adds to the problem of potential systemic failure that lies in the wings of complexity and chaos. Any system of sufficient complexity exhibits these characteristics and controlling such a system in the causal sense is merely wishful thinking. Much to the peril of those who momentarily thought they were on top of the concept of risk, the credit crisis of 2008 came to demonstrate that the monitoring of risk is ultimately rendered impossible. In fact, the very utterance of 'monitoring risk' 
constitutes a paradox since risk is by default designated to indicate the residual category of what can be controlled and monitored; that is, the exact opposite. Technology adds to the risk and does so, not only by establishing a 'technology risk' that affects other problem domains, but also by a systemic automation that reconstructs the operational basis of the financial system. Also, the trajectory depicted in the propositions extracted in this chapter should trouble us gravely: they illustrate a space where prediction systems like those suggested in Bethel, Leinweber et al. (2011) are - to some degree - of little consequence. Findings ways to develop a magnifying glass of automated transactions is not likely to help when automated decisions are forming an ever-increasing tsunami. Similarly, the very concept of riskaverse algorithms (Shen, Huang et al. 2014) violates the emergence of uncertainty and cannot account for the uncontrollable side-effects developed by technological interference.

Through the conceptual model developed in this chapter and the consolidation of its propositions in Table 1, it becomes clearer that deep technological penetration in the financial system reconstructs both our use of it as well as future applications. Technology is not a merely a tool that can be strictly controlled. It is a complex system; through automated decision-making processes that override human behaviour, technology alters the basic organizational structure through which financial decisions are executed and distorts the structure through which financial crises emerge.

\section{References}

Angell, I. (1993). "Intelligence: logical or biological." Communications of the ACM 36(7): 15-16\&119.

Arnuk, S. and J. Saluzzi (2012). Broken Markets: How High Frequency Trading and Predatory Practices on Wall Street Are Destroying Investor Confidence and Your Portfolio, FT Press.

Backhouse, J., et al. (2005). "Spotlight: New approaches to fighting moneylaundering." from demetis.wordpress.com. 
Bateson, G. (1972). Steps to an ecology of mind. New York,, Ballantine Books.

Baxter, G. and J. Cartlidge (2013). Flying by the seat of their pants: What can high frequency trading learn from aviation? ACM International Conference Proceeding Series.

Beer, S. (1985). Diagnosing the System for Organizations. New York, Wiley.

Bertalanffy, L. (1969). General System Theory. New York, George Braziller, Inc.

Bertalanffy, L. V. (1950). "An outline of general system theory." British Journal for the Philosophy of Science 1(2): 134-165.

Betancourt, L., et al. (2011). "Understanding the 'Flash Crash'." The CPA Journal.

Bethel, E. W., et al. (2011). Federal market information technology in the post flash crash era: Roles for supercomputing. WHPCF'11 - Proceedings of the 4th Workshop on High Performance Computational Finance, Co-located with SC'11.

Bloomberg (2015). "Sentiment Analysis of Financial News and Social Media."

Boulding, K. E. (1956). "General systems theory - the skeleton of science." Management science 2(3): 197-208.

Brandt, T. and D. Neumann (2015). "Chasing lemmings: Modeling IT-induced misperceptions about the strategic situation as a reason for flash crashes." Lournal of Management Information Systems 31(4): 88-108.

Bréhier, B. (2013). "High frequency trading: Should technological developments be considered a potential threat to financial markets and be subject to specific regulation?" ERA Forum 14(1): 69-80.

Brewer, P., et al. (2013). "Market microstructure design and flash crashes: A simulation approach." Journal of Applied Economics 16(2): 223-250.

Buchanan, I. (2010). A dictionary of critical theory, Oxford University Press.

Cai, C. X., et al. (2013). "Informed Trading and Market Structure." European Financial Management.

CFTC/SEC (2010). Findings Regarding the market events of May 6, 2010: Report of the staffs of the CFTC and SEC to the joint advisory committee on emerging regulatory issues.

Chaboud, A., et al. (2009). "Rise of the Machines: Algorithmic Trading in the Foreign Exchange Market." International Finance Discussion Papers 980.

Ciallella, G. (2015). Describing and Regulating High-Frequency Trading: A European Perspective. Handbook of High Frequency Trading: 95-110. 
Colford, P. (2014). "A leap forward in quarterly earnings stories." from http://blog.ap.org/2014/06/30/a-leap-forward-in-quarterly-earnings-stories/.

Demetis, D. and I. Angell (2006). "AML-related technologies: A Systemic Risk." Journal of Money Laundering Control 9(2): 157-172.

Dhillon, G. and J. Backhouse (2000). "Information System Security Management in the New Millennium." Communications of the ACM 43(7): 125-128.

Dreyfus, H. L., et al. (1986). Mind over machine : the power of human intuition and expertise in the era of the computer. Oxford, UK, B. Blackwell.

Edwards, C. (2010). "Flash and burn." Engineering and Technology 5(13): 50-53.

Erra, R. (2011). Malicious flash crash attacks by quote stuffing: This is the way the (financial) world could end. 10th European Conference on Information Warfare and Security 2011, ECIW 2011.

Geyer, F. (2002). "The march of self-reference." Kybernetes 31(7): 1021-1042.

Hammond, D. (2003). The science of synthesis : exploring the social implications of general systems theory. Boulder, University Press of Colorado.

Hendershott, T., et al. (2008). Does Algorithmic Trading Improve Liquitidy?

Lee, A. and D. Demetis (2016). Crafting Theory to Satisfy the Requirements of Systems Science. 49th Hawaii International Conference on System Sciences, IEEE: 5075-5084.

Luhmann, N. (1990). Essays on self reference. New York, Columbia University Press.

Luhmann, N. (1993). Risk: a sociological theory. New Brunswick, Transaction Publishers.

Luhmann, N. (1995). Social systems. Stanford, Calif, Stanford University Press.

Luhmann, N. (1997). "Globalization or World Society: How to Conceive of Modern Society." International Review of Sociology 7(1): 13-67.

Luhmann, N. (2002). Deconstruction as Second-Order Observing. Theories of Distinction: Redescribing the descriptions of modernity, Stanford University Press: 94-112.

Luhmann, N. (2002). Theories of Distinction: Redescribing the descriptions of modernity. Stanford, Stanford University Press. 
Luhmann, N. (2004). Law as a social system. Oxford ; New York, Oxford University Press.

Luhmann, N. (2006). "System as Difference." Organization 13(1): 37-57.

Maturana, H. and F. Varela (1998). The tree of knowledge: The biological roots of human understanding. Boston \& London, Shambhala.

Miller, J. G. (1978). Living systems. New York, McGraw-Hill.

Moeller, H.-G. (2006). Luhmann Explained. Peru, Illinois, Carus Publishing Company.

Moosa, I. (2015). "The regulation of high-frequency trading: A pragmatic view." Journal of Banking Regulation 16(1): 72-88.

Moosa, I. and V. Ramiah (2014). The Regulation of High-Frequency Trading: An Asian Perspective. Handbook of Asian Finance: REITs, Trading, and Fund Performance. 2: 153-170.

Rapoport, A. (1950). Science and the goals of man; a study in semantic orientation. New York,, Harper.

Reichel, A. (2011). "Technology as system: towards an autopoietic theory of technology." International Journal of Innovation and Sustainable Development 5(2/3): 105-118.

Schapiro, M. (2010). "Testimony Concerning the Severe Market Disruption on May 6, 2010." from http://www.sec.gov/news/testimony/2010/ts051110mls.htm.

Scharff, R. and V. Dusek, Eds. (2014). Philosophy of Technology: The Technological Condition, An Anthology, Wiley Blackwell.

Seidl, D. (2009). The Basic Concepts of Luhmann's Theory of Social Systems. Niklas Luhmann and Organization Studies, Copenhagen Business School Press: 21-53.

Shen, Y., et al. (2014). Risk-averse reinforcement learning for algorithmic trading. IEEE/IAFE Conference on Computational Intelligence for Financial Engineering, Proceedings (CIFEr).

Simmons, D. (2015). "How one tweet wiped \$8bn off Twitter's value." from http://www.bbc.co.uk/news/technology-32511932.

Skyttner, L. (2005). General systems theory : problems, perspectives, practice. Hackensack, NJ, World Scientific. 
Solon, O. (2011). "How a book about flies came to be priced $\$ 24$ million on Amazon." from http://www.wired.com/2011/04/amazon-flies-24-million/.

Sornette, D. and S. v. d. Becke (2011). Crashes and High Frequency Trading: An evaluation of risks posed by high-speed algorithmic trading. UK Government Foresight Project, The Future of Computer Trading in Financial Markets.

Stoll, H. R. (2014). "High Speed Equities Trading: 1993-2012." Asia-Pacific Journal of Financial Studies 43(6): 767-797.

Treleaven, P., et al. (2013). "Algorithmic trading review." Communications of the ACM 56(11): 76-85.

USagainstAleynikov (2009). "Proceedings before Magistrate Judge Kevin N. Fox." from http://www.securityprivacyandthelaw.com/uploads/file/Transcript (US v Aleynikov).pdf.

Van Lier, B. (2016). "From high frequency trading to self-organizing moral machines." International Journal of Technoethics 7(1): 34-50.

Von Foerster, H. (1951). Cybernetics, circular causal and feedback mechanisms in biological and social systems : transactions. New York, Josiah Macy, Jr. Foundation. 